Lepr Rev (2000) 71, 179-192

\title{
Mycobacterium $w$ vaccine, a useful adjuvant to multidrug therapy in multibacillary leprosy: a report on hospital based immunotherapeutic clinical trials with a follow-up of 1-7 years after treatment
}

\author{
PANKAJ SHARMA*, R. S. MISRA**, H. K. KAR***, \\ ASHOK MUKHERJEE+, D. PORICHA++, \\ HARVINDER KAUR* RAMA MUKHERJEE* \& \\ RAJNI RANI* \\ *National Institute of Immunology, New Delhi 110067, India \\ **Department of Dermatology and Leprology, Safdarjung Hospital, \\ New Delhi 110029, India \\ ***Department of Dermatology, Venereology and Leprology, \\ Dr Ram Manohar Lohia Hospital, New Delhi 110001, India \\ +Institute of Pathology, Indian Council of Medical Research, \\ Safdarjung Hospital Campus, New Delhi 110029, India \\ ++Pathology Laboratory, Parliament House Annexe Medical Centre, \\ New Delhi 110001, India
}

Accepted for publication 1 March 2000

Summary A vaccine based on autoclaved Mycobacterium $w$ was administered, in
addition to standard multidrug therapy (MDT), to 156 bacteriologically positive,
lepromin negative multibacillary leprosy patients compared to a well matched control
group of 145 patients with a similar type of disease who received a placebo injection
in addition to MDT. The MDT was given for a minimum period of 2 years and
continued until skin smear negativity, while the vaccine was given at 3 -month
intervals up to a maximum of eight doses. The fall in clinical scores and bacter-
iological indices was significantly more rapid in vaccinated patients, from 6 months
onward until years 2 or 3 of therapy. However, no difference was observed in the fall
in bacteriological index in the two groups from year 4 onwards. The number of LL
and BL patients released from therapy (RFT) following attainment of skin smear
negativity, after $24-29$ months of treatment was $84 / 133(63.1 \%)$ in vaccinated and
30/120 (25.0\%) in the placebo group; the difference was highly statistically
significant $(P<0.0001)$. In all, $90.2 \%$ patients $(146 / 162)$ converted from lepromin
negativity to positivity in the vaccine group, as against $37.9 \%(56 / 148)$ in the placebo
group. The average duration of lepromin positivity maintained following eight doses 
of vaccine administered over 2 years was 3.016 years in the vaccine and 0.920 years in the placebo group. Histological upgrading after 2 years of treatment in the LL type was observed in $34 / 84(40.5 \%)$ cases in the vaccine and $5 / 85(5.9 \%)$ cases in the placebo group, the difference being statistically significant $(P<0.001)$. The incidence of type 1 reactions was significantly higher $(30.5 \%)$ in the vaccine group than $(19.7 \%)$ in the placebo group $(P=0.0413)$; the difference was mainly observed in LL type $(P=0.009)$. The incidence of type 2 reactions was similar $(31.8$ and $34.6 \%)$ in vaccine and placebo groups. The vaccine did not precipitate neuritis or impairments over and above that encountered with MDT alone. After 5 years of follow-up following RFT, no incidence of bacteriological or clinical relapses was observed in both groups.

\section{Introduction}

Vaccines have played a dominant role in control of infectious diseases and it should hold true for leprosy also. The multidrug therapy (MDT) regimes for leprosy recommended by the World Health Organization (WHO) in 1982 have been implemented globally, largely as a result of encouragement from WHO and interest and cooperation on the part of national governments. This new strategy of operation has brought an appreciable reduction in prevalence rate of the disease, which stood around 10-12 million at the beginning of the 1980s, with nearly 4 million cases from India. These figures came down to 0.95 million and 0.5 million cases, respectively, by $1996 .^{1,2}$ Multibacillary (MB) leprosy was treated for a minimum of 2 years or until skin smear negativity as per initial guidelines, later on the recommended treatment schedule was for a fixed duration of 24 months and recently this has been further reduced to 12 months. The 2-year regime for MB leprosy is now considered desirable only in cases with a high bacteriological index (BI) who either deteriorate or do not improve after 12 months of therapy. ${ }^{3}$ Chemotherapy hardly affects cell mediated immunity (CMI) and hence the inherent immunological defect of MB patients is expected to continue even after complete bacteriological clearance.

The present approach of treating the MB cases with MDT of fixed duration leaves bacteriological clearance to the host $\mathrm{CMI} /$ macrophage system, which is already compromised in $\mathrm{MB}$ cases. However, this could be achieved by strengthening the host defence by other interventions such as an effective immunomodulator to hasten the bacterial clearance and clinical regression, and also inducing immuno-upgrading which would be more relevant with the short duration FDT. Skin smear positivity in MB cases is a concern, because the residual bacillary load puts the patient at risk of relapse and reactional episodes. Thus some form of immunomodulatory intervention along with chemotherapy may be desirable, whereby the patients could be rendered bacteriologically negative in a shorter time and the CMI status boosted to impart protection against reinfection.

The $M w$ vaccine, based on an atypical, saprophytic, cultivable, rapidly growing mycobacterium, has been under clinical trials at the urban leprosy centres of two major hospitals in Delhi, Safdarjung Hospital and Dr Ram Manohar Lohia Hospital, since 1987. The preliminary results of the study have been reported previously, though the follow-up was limited. ${ }^{4-10}$ This communication reports the complete analysis of the cases from the time of induction into the study, to date with a follow-up period of varying durations ( $1-7$ years) after release from treatment (RFT) following bacteriological negativity. At least 56 and $45 \%$ of 
patients in the vaccine and placebo groups, respectively, have been followed up for more than 5 years for reactional states, impairments and relapses.

\section{Materials and methods}

VACCINE, PLACEBO AND LEPROMIN PREPARATIONS

The vaccine is a suspension of killed Mycobacterium $w(M w)$ in physiological saline in the concentration of $10^{10}$ bacilli per $\mathrm{ml}$ as reported earlier. ${ }^{11}$ For plecebo, an autoclaved solution of micronized starch (Sarabhai Chemicals, Baroda, India) was used at a strength of $1 \mathrm{~g}$ per $100 \mathrm{ml}$ distilled water, dispensed in sterile vials. For lepromin testing, armadillo-derived lepromin containing $30-40 \times 10^{6}$ killed bacilli per $\mathrm{ml}$ was kindly made available by IMMLEP/TDR of WHO (Lot No. C-1, Preparation date 06/14/89, NHDC, Carville, LA, USA).

\section{VACCINE DOSE, REGIMEN AND ADMINISTRATION}

The first dose of vaccine was $1 \times 10^{9}$ autoclaved bacilli in $0.1 \mathrm{ml}$ physiological saline $(0.85 \%$ $\mathrm{NaCl}$ ). Subsequent doses contained half the number, i.e. $5 \times 10^{8}$ bacilli in $0.1 \mathrm{ml}$. The vaccine was administered intradermally in the deltoid region. In all, eight doses were given at 3month intervals, over a period of 2 years.

MULTIDRUG THERAPY (MDT)

In the initial phase, MDT consisted of 2 weeks of intensive therapy with $600 \mathrm{mg}$ rifampicin, $100 \mathrm{mg}$ clofazimine and $100 \mathrm{mg}$ dapsone daily. Subsequently, the patients received the WHO recommended regimen of $600 \mathrm{mg}$ rifampicin and $300 \mathrm{mg}$ clofazimine once a month, supervised, plus $100 \mathrm{mg}$ dapsone and $50 \mathrm{mg}$ clofazimine daily, self-administered. ${ }^{12}$ The MDT was given for a minimum period of 2 years and continued thereafter until skin smear negativity was attained.

\section{SUBJECTS AND STUDY DESIGN}

Permission of the Drug Controller General of India, and Institutional Ethics Committee was obtained before initiating the study. Written consent of the subjects was taken before inducting them in the trial. The enrolled subjects comprised active, untreated MB leprosy patients belonging to LL, BL and BB forms. They were bacteriologically positive in slit-skin smear examination and lepromin negative, thus consisting of a suitable class of patients where the immunomodulatory effects of boosting of CMI responses by an immunomodulator could be critically assessed. The diagnosis was confirmed by clinical, bacteriological and histopathological examination of the skin lesions. The patients were allotted to the vaccine and placebo groups in a randomized manner as per the codes supplied by the statistician. ${ }^{4}$ Standard MDT was administered to all cases; in addition, one group received the vaccine, whereas the other was given an injection of micronized starch (the identity of the injection was kept under code) as placebo.

The ongoing clinical trials had two series of cases. The first series (single blind) comprised $120 \mathrm{MB}$ leprosy patients, where vaccine codes were known to the Head of the 
clinic but not to the attending clinicians. The second (double blind) series of trial comprised $300 \mathrm{MB}$ patients, in which neither the evaluating agency nor the attending clinicians were aware of the identity of the injection administered. To ensure blinding, the upper part of the arm, i.e. the vaccination/placebo site, was covered with a cloth napkin by the non-medical assistant before the patient was examined by the Medical Officer. The same procedure was adopted while recording the lepromin response. The slides for BI smears were prepared by paramedical staff in the clinic and were coded with index numbers that were subsequently read by the medical of ficer at NII, without any clue to the identity of the vaccine codes. The vaccine codes were opened in 1992 for analysis of the data, after which the data from both the series were combined, as the protocol followed for treatment and follow-up in the two series were similar and the parameters of monitoring were identical. However, for the follow-up in the clinics, the blinding procedures mentioned above were continued during clinical examinations even after decoding.

The effects of the vaccine were assessed using criteria of clinical scoring, BI, lepromin status and histopathological features.

\section{CLINICAL SCORES}

The clinical scoring was done by the attending physician and a record of these was maintained in the form of body charting done at 6-month intervals. For the purpose of clinical assessment, Ramu's clinical scoring method was followed, in which a score of 1-4 is given to lesions depending on their characteristics as depicted in Table 1 . The body is divided into seven regions: (1) head and neck, (2) chest, abdomen and genitalia, (3) and (4) left and right upper limbs, (5) back and buttock, and finally (6) and (7) left and right lower limbs. Each region is scored independently from 1 to $4 .{ }^{13,14}$

In the initial part of the trial in the single blind series, the clinical scoring was done using the original Ramu's scoring system just described, where the maximum recordable score was 28. However, in the second phase, in order to make the scoring more qualitative, a modified system of clinical scoring was adopted in which each of the seven sectors of the body was further subdivided into four subsectors and given a score according to the clinical type of the lesion in each subsector. In this way there were $7 \times 4=28$ subsectors of the body and the maximum recordable score in the modified system was $28 \times 4=112$. The clinical details of the patients were recorded in clinical photographs taken at 6-month intervals.

B I

The skin-slit smear examinations for BI were carried out at 3-month intervals till the point of smear negativity, and thereafter at yearly intervals during follow-up. The smears were

Table 1. Ramus's system of clinical scoring

\begin{tabular}{ll}
\hline Score & Type of clinical lesions \\
\hline 1 & Macules with minimal erythema and shiny infiltration \\
2 & Well marked erythema and diffuse infiltration \\
3 & Thick infiltration with flat topped papules and plaques \\
4 & Infiltration with thick papulonodular lesions \\
\hline
\end{tabular}


collected from active lesions from six sites, stained using standard procedures and graded using the Ridley scale.

\section{LEPROMIN AND HISTOPATHOLOGICAL EVALUATION}

The lepromin status was assessed every 3 months during the first 2 years of therapy, and at 1-year intervals thereafter during the follow-up period. The histopathological monitoring comprised histopathological grading and classification. The tissue BI was carried out at 6-month intervals during immunochemotherapy.

\section{REACTIONAL STATES AND NEURITIS}

Type 1, type 2 reactions and neuritis were recognized by clinical features. A type 1 reaction was defined as visible changes in the skin lesions marked by prominence, erythematous hue and a subjective feeling of warmth, associated with or without constitutional symptoms. Type 2 reaction was defined as an episode of systemic illness with fever, aching, bony tenderness, joint pains with or without specific involvement of other organs such as eyes, kidneys, testis etc., also irrespective of appearance of characteristic lesions of erythema nodosum leprosum. An episode of neuritis was diagnosed on noticing thickened tender nerves in presence or absence of inflamed skin lesions. Peripheral nerves were examined for thickening and tenderness; superficial sensations (temperature, pain and touch) were tested using a temperature tester (supplied by WHO), pin and cotton wisp, respectively. Motor functions were assessed using voluntary muscle testing. ${ }^{15}$ In all three types of complications, only those episodes were counted which required management with non-steroidal anti-inflammatory drugs, prednisolone, clofazimine, etc. A proforrna sheet for leprosy reaction was filled in during each reactional episodes.

\section{STATISTICAL ANALYSIS}

The statistical analysis of the data on clinical scores and bacteriological indices was done using parametric tests, considering the observations for different time points. The comparison of decline between the vaccine and placebo groups has been done using two-sample $t$-test. The comparison of durations of lepromin positivity in the two groups has also been done using Student's $t$-test. The statistical significance of number of patients released from treatment (RFT) at various time periods, that of histopathological upgradation observed in patients from two groups, and the number of patients showing conversion to lepromin positivity, have been compared using the chi-square test.

\section{Results}

The initial status of patients were comparable in the vaccine and placebo groups in terms of clinical score, bacteriological indices, histopathological and lepromin status. 
Table 2. Changes in bacteriological indices (BI)

\begin{tabular}{|c|c|c|c|c|c|c|c|c|c|}
\hline \multirow{2}{*}{$\begin{array}{l}\text { Type of } \\
\text { disease }\end{array}$} & \multirow{2}{*}{$\begin{array}{c}\text { Group } \\
\text { (no. of cases) }\end{array}$} & \multirow{2}{*}{$\begin{array}{c}\text { Initial BI* } \\
{[\text { mean } \pm \mathrm{SE}(n)]}\end{array}$} & \multicolumn{7}{|c|}{ Cumulative mean decline in BI by different time points [mean decline \pm SE $(n)]$} \\
\hline & & & 6 months & 1 year & 18 months & 2 years & 3 years & 4 years & 5 years \\
\hline \multirow[t]{3}{*}{ LL } & Vaccine (83) & $3.77 \pm 0.13(83)$ & $1.04 \pm 0.14(83)$ & $1.50 \pm 0.15(83)$ & $2.14 \pm 0.14(83)$ & $2.68 \pm 0.12(83)$ & $3.23 \pm 0.09(80)$ & $3.44 \pm 0.07(65)$ & $3.66 \pm 0.06(47)$ \\
\hline & Placebo (81) & $3.90 \pm 0.12(81)$ & $0.51 \pm 0.13(81)$ & $0.89 \pm 0.12(80)$ & $1.25 \pm 0.13(79)$ & $1.74 \pm 0.14(79)$ & $2.91 \pm 0.11(73)$ & $3.44 \pm 0.09(62)$ & $3.73 \pm 0.07(42)$ \\
\hline & $\begin{array}{l}\text { Statistical } \\
\text { significance }\end{array}$ & NS & $t=2.72 P=0.007$ & $t=3.08 P=0.002$ & $t=4.47 P=<0.001$ & $t=4.90 P=<0.001$ & $t=2.05 P=0.04$ & $t=0.04 P=0.96$ & $t=0.72 P=0.47$ \\
\hline \multirow[t]{3}{*}{ BL } & Vaccine (48) & $2.37 \pm 0.16(48)$ & $1.16 \pm 0.14(48)$ & $1.60 \pm 0.11(48)$ & $2.08 \pm 0.06(48)$ & $2.15 \pm 0.05(48)$ & $2.37 \pm 0.01(41)$ & $2.37 \pm 0.01(29)$ & $2.37 \pm 0.01(24)$ \\
\hline & Placebo (41) & $2.12 \pm 0.19(41)$ & $0.47 \pm 0.17(41)$ & $0.74 \pm 0.15(41)$ & $1.12 \pm 0.10(41)$ & $1.54 \pm 0.09(41)$ & $1.83 \pm 0.08(41)$ & $2.24 \pm 0.03(41)$ & $2.24 \pm 0.57(41)$ \\
\hline & $\begin{array}{l}\text { Statistical } \\
\text { significance }\end{array}$ & NS & $t=3.04 P=0.003$ & $t=4.36 P=<0.001$ & $t=7.54 P=<0.001$ & $t=5.78 P=<0.001$ & $t=8.09 P=<0.001$ & NS & NS \\
\hline \multirow[t]{3}{*}{ BB } & Vaccine (24) & $0.58 \pm 0.07(24)$ & $0.39 \pm 0.04(24)$ & $0.52 \pm 0.02(24)$ & $0.52 \pm 0.02(24)$ & $0.52 \pm 0.02(24)$ & $0.52 \pm 0.02(19)$ & $0.52 \pm 0.02(14)$ & $0.52 \pm 0.02(12)$ \\
\hline & Placebo (23) & $1.03 \pm 0.20(23)$ & $0.45 \pm 0.13(23)$ & $0.60 \pm 0.13(23)$ & $0.73 \pm 0.10$ & $0.86 \pm 0.06$ & $0.95 \pm 0.03(20)$ & $0.95 \pm 0.03(13)$ & $0.95 \pm 0.03$ \\
\hline & $\begin{array}{l}\text { Statistical } \\
\text { significance }\end{array}$ & NS & $t=0.46 P=0.64$ & $t=0.54 P=0.58$ & NS & NS & NS & NS & NS \\
\hline
\end{tabular}

*Initial $\mathrm{BI}=$ bacteriological index at the time of induction.

$\mathrm{NS}=$ not significant. 
immunochemotherapy and 3 years of chemotherapy. Although about $50 \%$ of patients were followed up for over 5 years, the BI has been shown only for 5 years, since they became bacteriologically negative. No relapses were observed. Grouped according to the histological criteria, a significantly faster rate of $\mathrm{BI}$ decline was observed in the LL and BL vaccine groups from 6 months to 3 years, as compared to the placebo group; thereafter the difference in the two groups was non-significant. The majority of cases attained BI negativity in the vaccine group after 2 years of therapy, while the fall in BI in the placebo group occurred gradually and patients attained bacteriological negativity after 4-5 years of therapy. In BB type, the initial BI itself was very low and following therapy, no statistically significant difference was observed between the vaccine and placebo groups, at any stage of therapy.

\section{CHANGES IN CLINICAL SCORES}

Table 3 shows the mean values of clinical score (CS) at different time points over a period of 5 years from the commencement of therapy. Clinically, this was evident as regression and flattening of papulonodular lesions and plaques, and disappearance of hypopigmented lesions and diffuse infiltration. The statistically significant difference between the vaccine and placebo groups $(P<0.001)$ is observed in LL and BL leprosy after 2 years of therapy. In BB leprosy, however, the difference between the vaccine and placebo groups was not statistically significant at any stage of treatment.

\section{CHANGES IN LEPROMIN STATUS}

At induction, all patients were lepromin negative in their late (Mitsuda) response. With progressive immunization, there was a gradual increase in number of patients showing conversion to lepromin positivity. After 2 years of immunochemotherapy, $94.4 \%$ of LL patients converted to positivity in the vaccine group as compared to $7.3 \%$ in the placebo group. In BL leprosy, $64 \%$ of cases converted to positivity in vaccine as against $14.6 \%$ in the placebo group and in BB type, the corresponding figures were 94.4 and 53\% for vaccine and placebo groups, respectively. The differences between vaccine and placebo groups, in respective leprosy types, were highly statistically significant $(P<0.001){ }^{16}$

Table 4 shows the durations for which leprornin positivity was sustained. The majority of the patients in both vaccine and placebo groups reverted back to lepromin negativity during late stages of follow-up. The average durations of positivity in LL, BL and BB types were $2.38,2.22$ and 4.45 years in the vaccine group, and $0.21,0.65$ and 1.90 years in the placebo group, respectively. The differences between vaccine and placebo groups were statistically significant in all three leprosy types. The overall duration of lepromin positivity in all three types of leprosy, taking into account the cases who did not convert to lepromin positivity at any stage, was calculated as 3.016 years in the vaccine group and 0.920 years in the placebo group.

\section{RELEASE FROM TREATMENT}

Patients were released from treatment (RFT) after three consecutive slit smears at monthly intervals were negative for acid fast bacilli (AFB). Figure 1 depicts the percentages of patients released from therapy at different ranges of therapy duration, after which they became skin smear negative. In LL type, 45.2\% (38/84) patients attained skin smear 
Table 3. Changes in clinical scores

\begin{tabular}{|c|c|c|c|c|c|c|c|}
\hline \multirow{2}{*}{$\begin{array}{l}\text { Type } \\
\text { of } \\
\text { disease }\end{array}$} & \multirow{2}{*}{$\begin{array}{l}\text { Group } \\
\text { (no. of } \\
\text { cases) }\end{array}$} & \multirow{2}{*}{$\begin{array}{c}\text { Initial* }^{*} \\
{[\text { mean } \pm \text { SE }(n)]}\end{array}$} & \multicolumn{5}{|c|}{ Mean clinical scores at different time points [mean $\pm \operatorname{SE}(n)]$} \\
\hline & & & 1 year & 2 year & 3 year & 4 year & 5 year \\
\hline \multirow[t]{3}{*}{ LL } & Vaccine $(83)$ & $52.6 \pm 2.4(83)$ & $31.7 \pm 2.1(83)$ & $17.0 \pm 1.3(83)$ & $8.5 \pm 1.0(53)$ & $4.2 \pm 0.8(38)$ & $2.7 \pm 0.6(34)$ \\
\hline & Placebo (81) & $51.3 \pm 2.2(81)$ & $33.6 \pm 1.8(80)$ & $26.4 \pm 2.1(78)$ & $14.6 \pm 1.8(45)$ & $9.0 \pm 1.45(29)$ & $4.17 \pm 1.4(29)$ \\
\hline & Statistical significance & NS & $t=0.67 P=0.501$ & $t=3.80 P=<0.001$ & $t=2.92 P=0.004$ & $t=2.85 P=0.005$ & $t=0.90 P=0.369$ \\
\hline \multirow[t]{3}{*}{ BL } & Vaccine $(48)$ & $41.9 \pm 3.2(48)$ & $20.5 \pm 1.8(48)$ & $9.0 \pm 1.1(47)$ & $5.0 \pm 1.3(33)$ & $0.87 \pm 0.4$ & $1.3 \pm 0.8(20)$ \\
\hline & Placebo (41) & $41.1 \pm 3.2(41)$ & $22.6 \pm 2.4(41)$ & $15.6 \pm 1.8(40)$ & $11.3 \pm 2.8(18)$ & $5.1 \pm 1.6(15)$ & $0.6 \pm 0.1(21)$ \\
\hline & Statistical significance & NS & $t=0.70 P=0.484$ & $t=3.09 P=0.002$ & $t=2.02 P=0.048$ & $t=2.38 P=0.024$ & $t=0.18 \mathrm{NS}$ \\
\hline \multirow[t]{3}{*}{ BB } & Vaccine (24) & $34.7 \pm 4.6$ & $15.6 \pm 3.2$ & $9.2 \pm 2.4$ & $5.4 \pm 2.8$ & $3.9 \pm 2.6$ & $0.2 \pm 0.2$ \\
\hline & Placebo (23) & $36.9 \pm 3.6(23)$ & $21.7 \pm 1.8$ & $13.9 \pm 2.3(22)$ & $9.7 \pm 2.09(12)$ & $2.0 \pm 1.0(6)$ & $0.6 \pm 0.3(10)$ \\
\hline & Statistical significance & $t=0.37 \mathrm{NS}$ & $t=1.63 P=0.109$ & $t=1.36 P=0.179$ & $t=1.22 \mathrm{NS}$ & $t=0.67 P=0.512$ & $t=0.75 P=0.46$ \\
\hline
\end{tabular}

*Initial = clinical score index at the time of induction.

NS $=$ not significant. 
Table 4. Duration of lepromin positivity in varous groups

\begin{tabular}{lccc}
\hline & \multicolumn{2}{l}{ Sustained long-term positivity (years) [mean \pm SE (no. of cases)] } \\
\cline { 2 - 4 } Total cases & LL & BL & BB \\
\hline Vaccine & $2.38 \pm 0.28(62)$ & $2.22 \pm 0.31(44)$ & $4.45 \pm 0.63(22)$ \\
Placebo & $0.21 \pm 0.11(76)$ & $0.65 \pm 0.29(33)$ & $1.90(14)$ \\
Statistical significance & $P<0.001$ & $P=0.001$ & $P=0.01$ \\
\hline
\end{tabular}

Overall positivity in all three types of leprosy, i.e. LL, BL and BB following 8 doses of immunotherapy and chemotherapy: vaccine group: 3.016 years; placebo group: 0.920 years.

negativity after 24-29 months of therapy in the vaccine group, as against $20.2 \%(16 / 79)$ patients in placebo. In BL type the corresponding figures were $93.8 \%(46 / 49)$ for vaccine and $34.1 \%$ (14/41) for placebo group. Similarly, the figures in the BB type were $95.8 \%(23 / 24)$ and $78.2 \%(18 / 23)$, respectively.
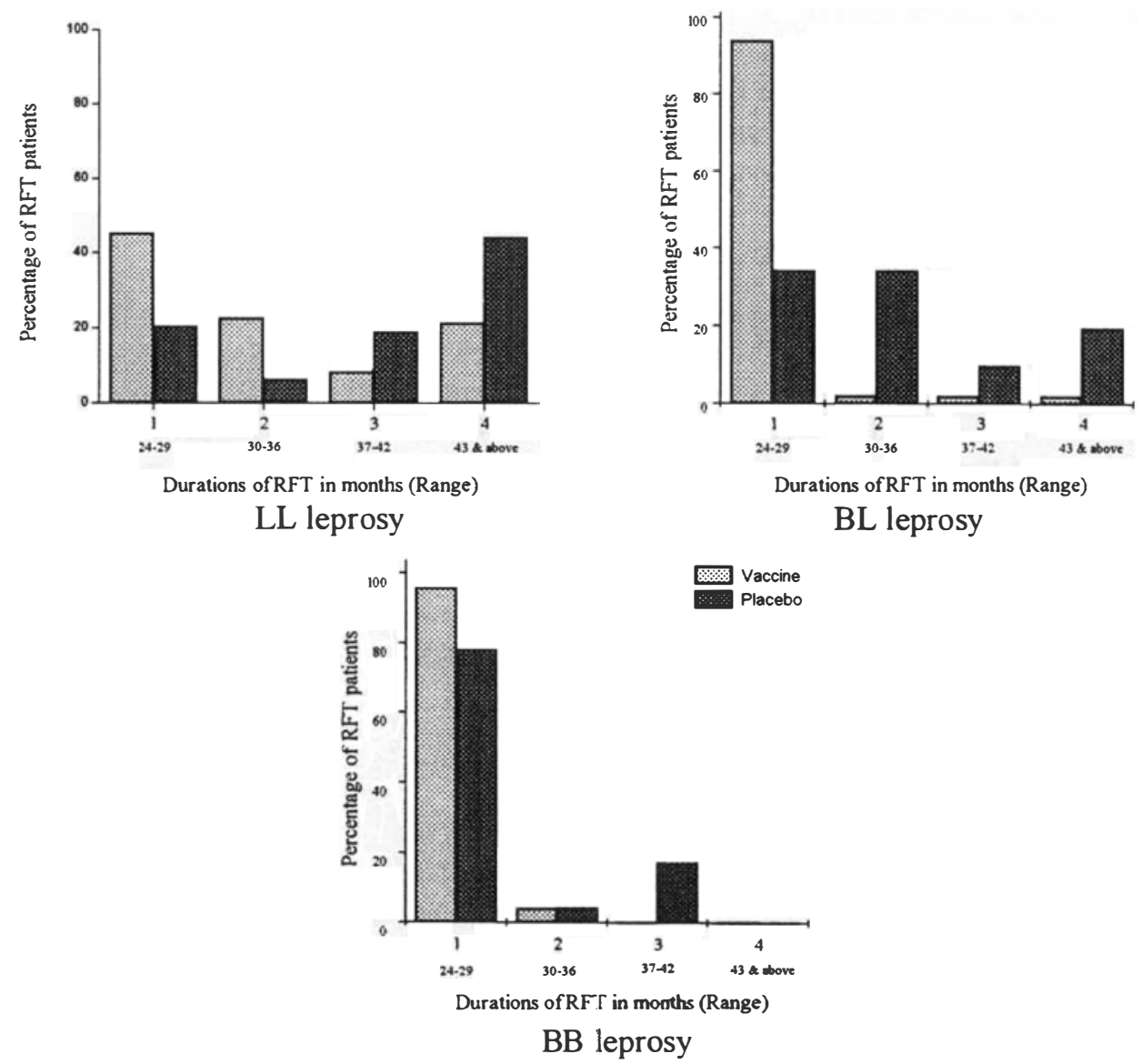

Figure 1. Percentages of patients released from treatment (RTF) following attainment of skin smear negativity in LL, $\mathrm{BL}$ and $\mathrm{BB}$ leprosy types in vaccine and placebo groups. 
Table 5. Incidence of reactional episodes and neuritis

\begin{tabular}{|c|c|c|c|c|c|c|c|c|c|}
\hline \multirow[t]{2}{*}{ Group (304) } & \multicolumn{3}{|c|}{ Type 1 reaction } & \multicolumn{3}{|c|}{ Type 2 reaction } & \multicolumn{3}{|c|}{ Neuritis } \\
\hline & LL (84) & BL (49) & BB (24) & LL (84) & BL (49) & BB (24) & LL (84) & BL (49) & BB (24) \\
\hline \multirow{2}{*}{$\begin{array}{l}\text { Vaccine } \\
\text { (157) }\end{array}$} & $25(29.7 \%)$ & $17(34.6 \%)$ & $6(25.0 \%)$ & $42(50.0 \%)$ & $7(14.2 \%)$ & $1(4.1 \%)$ & $31(36.9 \%)$ & $15(30.6 \%)$ & $5(20.8 \%)$ \\
\hline & \multicolumn{3}{|c|}{48 patients $(30.5 \%)$} & \multicolumn{3}{|c|}{50 patients $(31.8 \%)$} & \multicolumn{3}{|c|}{51 patients $(32.4 \%)$} \\
\hline Placebo & LL (83) & BL (41) & BB (23) & LL (83) & BL (41) & BB (23) & LL (83) & BL (41) & $\mathrm{BB}(23)$ \\
\hline \multirow[t]{3}{*}{ (147) } & $10(12.0 \%)$ & $10(24.3 \%)$ & $9(39.1 \%)$ & $43(51.8 \%)$ & $7(17.1 \%)$ & $1(4.3 \%)$ & $36(43.3 \%)$ & $12(29.2 \%)$ & $6(26.1 \%)$ \\
\hline & \multicolumn{3}{|c|}{29 patients $(19.7 \%)$} & \multicolumn{3}{|c|}{51 patients $(34.6 \%)$} & \multicolumn{3}{|c|}{54 patients $(36.7 \%)$} \\
\hline & \multicolumn{3}{|c|}{$P=0.0413 *$} & \multicolumn{3}{|c|}{$P=0.686$} & \multicolumn{3}{|c|}{$P=0.510$} \\
\hline$P$ value & 0.009 & 0.406 & 0.468 & 0.937 & 0.943 & 0.489 & 0.487 & 0.926 & 0.936 \\
\hline
\end{tabular}

*The $P$ values were calculated using chi-square. The value for type 1 reaction for all categories combined $(P=$ 0.0413 ), after Bonferroni's correction becomes $P=0.124$. The significance for the same figures calculated by Mantel-Haenszel chi-square test is $P=0.137$. Power size calculation for BB type is $70 \%$ for type 1 reactions.

The overall number of cases attaining skin smear negativity after 24-29 months of treatment in LL and BL types of leprosy combined, was 84/133 (63.1\%) and 30/120 (25.0\%) in the vaccine and placebo groups, respectively, and the difference was highly significant statistically $(P<0.0001)$.

\section{INCIDENCE OF REACTIONS AND NEURITIS}

Table 5 presents the number of patients experiencing type 1, type 2 reactions and neuritis in the two groups. The numbers of such patients have been compared in total, as well as against the respective categories from vaccine and placebo groups. There is no statistically significant difference with respect to type 2 reactions and neuritis in any leprosy type. However, the incidence of type 1 reactions was higher in the vaccine group as a whole $(P=0.041$, odds ratio 1.79 ), mainly because of higher incidence observed in LL leprosy, i.e. 25 patients out of $84(29.7 \%)$ in vaccine group, as against 10 out of $83(12.0 \%)$ in the placebo group; this difference is statistically significant $(P=0.009)$. However, the same difference was not significant after the $P$ value was corrected for the number of variables, and also when calculated by multivariate analysis. The higher rate of type 1 reaction in the vaccine group was not associated with any rise in the rate of sensorimotor impairments; details are reported elsewhere. $^{17}$

\section{HISTOLOGICAL CHANGES}

Histological monitoring was done through skin biopsies taken every 6 months from the same site. Histological improvement, i.e. histological upgrading and/or granuloma clearance, was seen in 34/84 (40.5\%) of vaccinated LL patients at 24 months, as compared to 5/85 (5.9\%) in control group $(P<0.001)$. Of these 34 cases showing histopathological upgrading in the vaccine group, 14 showed a complete disappearance of dermal granuloma giving a picture of non-specific infiltration (NSI) at the end of 24 months of treatment. This was more evocatively demonstrated in BL vaccinated patients, where 35 out of total 47 cases showed upgrading $(74.5 \%)$ and 32 of those 35 (91.4\%) showed NSI. The overall rates of 
Table 6. Post-RFT follow-up of MB leprosy patients treated with MDT with/without $M w$ vaccine

\begin{tabular}{|c|c|c|c|c|c|c|}
\hline Group (304) & $5-10$ years & $2-5$ years & $1-2$ years & $<1$ years & $\begin{array}{c}\text { Not } \\
\text { followed } \\
\text { up }\end{array}$ & $\begin{array}{c}\text { Average } \\
\text { follow-up } \\
\text { period* }\end{array}$ \\
\hline Vaccine (157) & $88(56.0 \%)$ & $38(24.2 \%)$ & $7(4.4 \%)$ & $8(5.1 \%)$ & $16(10.2 \%)$ & 5.60 years \\
\hline Placebo (147) & $66(44.9 \%)$ & $35(23.8 \%)$ & $9(6.1 \%)$ & $9(6.1 \%)$ & $28(19.0 \%)$ & 5.06 years \\
\hline
\end{tabular}

*Average follow-up period calculated excluding those not followed up.

histopathological improvement observed at 12 and 24 months demonstrate a statistically significant difference in the vaccine and placebo groups $(P<0.001)$.

Patients clinically classified as BB had varied initial histological features of indeterminate, BT, BT/BB or BB types. A follow-up of these patients for a period of 2 years did not reveal any appreciable differences in the two groups.

LOCAL REACTIONS TO VACCINE

The clinical experience of the trial has shown that the vaccine was well tolerated, without any major side effects. Local erythema and induration at the injection site, sometimes leading to ulcer formation, was the only problem observed in a few cases. These healed spontaneously in about a week's time.

POST-RFT FOLLOW-UP

Table 6 shows the number of patients that could be followed up after release from therapy for different durations. The average follow-up period was 5.60 years in vaccine and 5.06 years in the placebo group.

\section{Discussion}

Several candidate vaccines have been tested for their immunotherapeutic potential, viz. (i) killed M. leprae + BCG by Convitt et al. ${ }^{18}$, (ii) Indian Cancer Research Centre strain (ICRC) by Bapat and Dev et al. ${ }^{19}$ and (iii) $M$. vaccae, by Stanford et al. ${ }^{20}$ However, the clinical trials with $M w$ are unique in several respects. These are the first trials where immunotherapeutic effects of an immunomodulator have been critically assessed in active multibacillary leprosy patients, by clinical, bacteriological, immunological and histological parameters.

$M w$ vaccine is based on an atypical, saprophytic, cultivable, rapidly growing mycobacterium. It resembles the bacilli included in Runyon's group IV, but differs in one respect or another from bacilli presently included in that group. ${ }^{21,22}$ The recent studies based on nucleotide sequence in a polymorphic region of $65 \mathrm{kD}$ gene indicate that $M w$ is a new species $^{23}$. The basic research work of development of $M w$ vaccine began in the late 1970 s and the background studies relating to its selection as a candidate anti-leprosy vaccine have been reported. ${ }^{24-29}$ The phase I clinical trials were conducted in 1981 by Chaudhary et al. at Calcutta. $^{30}$

Patients receiving $M w$ vaccine showed marked improvement in clinical features resulting in reduction of infiltration and rapid clearance of papulonodular lesions. As assessed through 
Ramu's clinical scores, ${ }^{13,14}$ vaccinated patients showed a statistically significant fall in scores in LL and BL types of leprosy after 2 years of therapy $(P<0.001)$. The BI decline in our study was faster among vaccinated patients; as many as $63.1 \%(84 / 133)$ BL and LL patients with high initial BI in the vaccine group attained bacteriological negativity within 24-29 months of treatment. The corresponding figure in the placebo group was $25.0 \%(30 / 120)$ and the difference was highly significant statistically $(P<0.0001)$. The histological improvement in the form of either upgrade or disappearance of granuloma was significantly more in vaccinated $\mathrm{BL}$ and LL patients $(P<0.001)$, as observed after 1 and 2 years of therapy. In both types together, 69 out of $131(52.6 \%)$ showed histological upgrade, of which 46 $(66.6 \%)$ showed a complete disappearance of dermal granuloma resulting in a histological picture of non-specific infiltration (NSI). In BB patients, histological upgrade was observed in both vaccine and control groups with little variation, which was not statistically significant.

Another beneficial effect of $M w$ vaccine as an immunotherapeutic supplement to MDT has been its impact on boosting the CMI of patients, as demonstrated by positive lepromin conversion. The duration of lepromin positive status in the cases receiving $M w$ vaccine was much longer as compared to those receiving the placebo. The overall duration of lepromin positivity in the vaccine and placebo groups, following administration of eight doses over a period of nearly 2 years, was 3.016 and 0.920 years, respectively. This gives some indication of the time period when a patient should receive a booster vaccination so as to keep them lepromin positive and prevent relapse or reinfection. A reasonable approach would be to administer a booster dose at an interval of 3 years after the patient has completed MDT.

The upgrade of CMI responses by the vaccine is also reflected by the higher incidence of type 1 reactions in vaccinated patients, notably in LL type. This was seen in $29.7 \%(25 / 84)$ patients in vaccine, as compared to $12 \%(10 / 83)$ in the control group. The number of patients experiencing type 2 reactions in the two groups did not show any statistically significant difference. Though not a parameter of the study, it was imperative to monitor incidence of reactions and impairments when using immunomodulators in leprosy. It was reassuring to note that for neuritis and deformities, $M w$ vaccine did not lead to any higher incidence over and above that observed with chemotherapy alone. This was also corroborated histopathologically, where vaccination did not precipitate inflammation of dermal nerve twigs. ${ }^{6}$

To sum up, the overall clinical, bacteriological and histological improvement amongst vaccinated patients was reflected by attainment of early skin-smear negativity and clinical inactivity, resulting in a shorter duration of effective treatment. Statistically significant number of LL and BL patients were released from treatment after 24-29 months of therapy $(P<0.0001)$, thus vaccinated patients had less morbidity, became BI negative faster. No case of clinical or bacteriological relapse was observed in the vaccine and placebo groups probably because MDT was continued till skin smear negativity in both the groups. The complete clearance of bacillary load could be a factor behind prevention of relapse/ reinfection in the cases so far followed. It may be noted that in high initial BI cases, such a bacteriologically negative status is attained in the placebo group towards years 4 or 5 of chemotherapy while the similar status is attained in years 2 or 3 following immunochemotherapy as depicted in Figure 1. This shows that a significant number of patients with high BI (63.1\% of LL and BL patients combined) could be rendered bacteriologically negative after 24-29 months of treatment. In other words, the results obtained with chemotherapy alone in 4-5 years could be achieved within 2-3 years following addition of immunotherapy with $M w$ vaccine to standard MDT as an adjunct. 
The 7th WHO Expert Committee on Leprosy recommended on the basis of multicentric trials that it is possible to reduce the duration of the current WHO MDT regimen for MB leprosy, from 24 months to 12 months. The WHO Leprosy Elimination Advisory Group (LEAG) has, in its meeting on 16-17 July, 1997, endorsed the technical recommendation of the 7th Expert Committee and urged the national governments to implement the same. This communication intends to convey that in spite of visible changes in the disease scenario in the last decade, the relevance of immunotherapeutic intervention should not be undervalued and there are a number of problematic multibacillary leprosy cases (e.g. highly bacilliferous, slow or non-responsive MB cases) which can be dealt with successfully through this approach.

\section{Acknowledgements}

The clinical trials were supported from a grant from the Department of Biotechnology, Ministry of Science and Technology, Government of India. The guidance of Dr Padam Singh, Director, Institute of Research in Medical Statistics, New Delhi and meticulous hard work of Dr Abha Aggarwal in carrying out the statistical analysis of the data is gratefully acknowledged. The technical assistance of Mr Dinesh Negi, Mr Amarnath Prasad and Mr Anil Bobbin in day-to-day work of the clinics is also gratefully acknowledged. Above all, the investigators feel immensely indebted to the patients of this study without whose cooperation such a long study would not have been possible.

\section{References}

1 World Health Organization. WHO Expert Committee on leprosy, 6th report. Tech Rep Ser, 1988; 768: 14-15.

2 WHO. Global plan of action for the elimination of leprosy, updated 1996. Lepr Rev, 1997; 68: 104-107.

3 MDT. Questions and answers (revised 1997). Action programme for elimination of leprosy. WHO/LEP/97.8

${ }^{4}$ Talwar GP, Mukherjee R, Zaheer SA, Sharma AK, Kar HK, Misra RS, Mukherjee A. Present approaches to immunotherapy and immunoprophylaxis in leprosy. In: Talwar GP (ed.), Progress in vaccinology, vol. II. Springer-Verlag, New York, 1989, pp 301-311.

5 Talwar GP, Zaheer SA, Suresh NR, Parida SK, Mukherjee R, Singh IG, Sharma AK, Kar HK, Misra RS, Mukherjee A. Immunotherapeutic trials with a candidate anti leprosy vaccine based on Mycobacterium w. Trop Med Parasitol, 1991; 41: 369-370.

${ }^{6}$ Mukherjee A, Zaheer SA, Sharma AK, Misra RS, Kar HK, Mukherjee R, Talwar GP. Histopathological monitoring of immunotherapeutic trials with Mycobacterium w. Int J Lepr, 1992; 60: 28-35.

7 Zaheer SA, Suresh NR, Kar HK, Sharma AK, Mukherjee A, Mukherjee R, Talwar GP. Immunological upgrading with combined immunotherapy and chemotherapy in an LL patient. A case report. Lepr Rev, 1991; 61: 297-302.

8 Zaheer SA, Misra RS, Sharma AK, Beena KR, Kar HK, Mukherjee A, Mukherjee R, Walia R, Talwar GP. Immunotherapy with Mycobacterium $w$ vaccine decreases the incidence and severity of type 2 (ENL) reactions. Lepr Rev, 1993; 64: 7-14.

9 Zaheer SA, Mukherjee R, Ram Kumar B, Misra RS, Sharma AK, Kar HK, Kaur H, Nair SK, Mukherjee A, Talwar GP. Combined multidrug and Mycobacterium $w$ vaccine therapy in patients with multibacillary leprosy. $J$ Infect Dis, 1993; 167: 401-410.

10 Kar HK, Sharma AK, Misra RS et al. Induction of lepromin positivity by a candidate anti-leprosy vaccine Mycobacterium $w$ in lepromin negative healthy contacts of multibacillary leprosy patients. Ind J Lepr, 1992; 64: 495-500.

11 Talwar GP, Zaheer SA, Mukher jee R, Walia R, Misra RS, Sharma AK, Kar HK, Mukherjee A, Parida SK, Suresh NR, Nair SK, Pandey RM. Immunotherapeutic effects of a vaccine based on a saprophytic cultivable mycobacterium, Mycobacterium w, in multibacillary leprosy patients. Vaccine, 1990; 8: 121-129.

12 World Health Organization. Treatment of leprosy. In: A guide to leprosy control. WHO, Geneva, 1980, pp 23-32.

13 Ramu G, Desikan KV. A follow-up study of borderline tuberculoid leprosy under sulphone monotherapy. Ind $J$ Lepr, 1988; 60: 26-33. 
14 Iyar CGS, Balakrishnan, Ramu G. A comparison of low and conventional dosages of dapsone in the treatment of lepromatous leprosy in India. Lepr Ind, 1977; 49: 372-388.

15 Goodwin CS. The use of voluntary muscle testing in leprosy neuritis. Lepr Rev, 1968; 39: 209-216.

16 Sharma P, Kar HK, Misra RS, Mukherjee A, Kaur H, Mukherjee R, Rani R. Induction of lepromin positivity following immuno-chemotherapy with Mycobacterium $w$ anti-leprosy vaccine and its impact on bacteriological clearance in MB leprosy. Int J Lepr, 1999; 67: 259-269

17 Sharma P, Kar HK, Misra RS, Mukher jee A, Kaur H, Mukherjee R, Rani R. Disabilities in multibacillary leprosy following MDT with/without immunotherapy with Mycobacterium $w$ anti-leprosy vaccine. Int J Lepr, 1999; 67: $250-258$

18 Convit J, Aranzazu N, Pinardi ME, Reyes O, Alvarado J. Immunotherapy with a mixture of Mycobacterium leprae and BCG in different forms of leprosy and in Mitsuda negative contacts. Int J Lepr, 1982; 50: 415-424.

19 Deo MG, Bapat CV, Bhalerao V, Chaturvedi RM, Chulawala RG, Bhatki WS. Anti-leprosy potentials of the ICRC vaccine: a study in patients and healthy volunteers. Int J Lepr, 1983; 51: 540-549.

20 Stanford JL, Rook GAW, Bahr GM et al. Mycobacterium vaccae in immuno-prophylaxis and immunotherapy of leprosy and tuberculosis. Vaccine, 1990; 8: 525-530.

21 Saxena VK, Singh US, Singh AK. Bacteriological study of a rapidly growing strain of mycobacterium. Lepr Ind, 1978; 50: 588-596.

${ }^{22}$ Katoch VM. A report on the biochemical analysis of Mycobacterium w. Lepr Ind, 1981; 53: 385-389.

23 Reddy PP, Amin AG, Khandekar PS, Talwar GP. Molecular definition of unique species status of Mycobacterium $w$; a candidate leprosy vaccine strain. Int J Lepr, 1994; 62: 229-236.

${ }^{24}$ Talwar GP. Towards development of a vaccine against leprosy. Lepr Ind, 1978; 50: 492-497.

25 Mustafa AS, Talwar GP. Five cultivable mycobacterial strains giving blast transformations and leukocyte migration - inhibition of leukocytes analogous to Mycobacterium leprae. Lepr Ind, 1978; 50: 498-508.

${ }^{26}$ Mustafa AS, Talwar GP. Delayed hypersensitivity skin reactions to homologous and heterologous antigens in guinea pigs immunized with $M$. leprae and four selected cultivable mycobacterial strains. Lepr Ind, 1978; 50: 509-519.

27 Fotedar A, Mehra NK, Mustafa AS, Talwar GP. Local reactions to intra-dermal instillation of Mycobacterium w and ICRC bacilli in mice. Lepr Ind, 1978; 50: 520-533.

${ }^{28}$ Mustafa AS, Talwar, GP. Enlargement of draining lymph nodes in mice by four selected cultivable strains of mycobacteria. Lepr Ind, 1978; 50: 534-538.

29 Mustafa AS, Talwar GP. Early and late reactions in tuberculoid and lepromatous leprosy patients with lepromins from Mycobacterium leprae and five selected cultivable mycobacteria. Lepr Ind, 1978; 50: 566-571.

30 Chaudhuri S, Fotedar A, Talwar GP. Lepromin conversion in repeatedly lepromin negative BL/LL patients after immunization with autoclaved Mycobacterium w. Int J Lepr, 1983; 51: 159-168. 